\title{
THE QUESTION-AND-ANSWER LOGIC OF HISTORICAL CONTEXT
}

Christopher Fear, University of Exeter

Christopher Fear

Department of Politics

Amory Building

Rennes Drive

Exeter

EX4 4RJ

(+44) 7531558085

C.Fear@ex.ac.uk 
THE QUESTION-AND-ANSWER LOGIC OF HISTORICAL CONTEXT

\begin{abstract}
Quentin Skinner has enduringly insisted that a past text cannot be 'understood' without the reader knowing something about its historical and linguistic context. But since the 1970s he has been attacked on this central point of all his work by authors maintaining that the text itself is the fundamental guide to the author's intention, and that a separate study of the context cannot tell the historian anything that the text itself could not. Mark Bevir has spent much of the last twenty years repeating a similar counter-argument. Although 'study the linguistic context' might be a useful heuristic maxim, Bevir says, it does not express a necessary or sufficient condition for understanding. But Skinner is right, and one of the figures he has consistently identified as a formative inspiration, R. G. Collingwood, has already (in his work of the 1930s) shown why. What Collingwood calls his 'logic of question and answer' explains why the historian cannot answer his characteristic 'intention' question about past texts without knowing the context of problems to which authors think they are offering solutions. The study of context is neither 'prior' (as Bevir incorrectly supposes) nor 'separate' (as Skinner inaccurately says), but it $i$, as Skinner maintains, nevertheless impossible to grasp an author's intention without it. This 'logic of question and answer' also explains why, in history, dismissing the study of context is in fact a prejudgement of evidence yet unseen.
\end{abstract}

Key words history of ideas, methodology, context, Quentin Skinner, R. G.

\title{
Collingwood
}




\section{Context and its critics}

For Quentin Skinner, understanding a text means knowing what an author thought he was 'doing' with it, and in it, and in order to know what he was 'doing' it is necessary, Skinner says, to know something of the situation in which he saw himself the 'context' without which the author's intentions make no sense (1969: 48-9). We might be able to understand something about what an author thought he was doing by examining a text in isolation but, unless we consider the relevant features of the text's context, we cannot grasp what he was doing. Our understanding of that text, in short, will be impoverished.

This 'contextualism' came under instant fire in the early 1970s in articles by literary theorists such as Anthony Savile and S. H. Olsen ${ }^{1}$ (Skinner, 1975: 217). These critics maintained that the fundamental guide to an author's intentions in writing is provided by the text itself - or at least that is how historians of ideas ought to approach texts. A separate study of an author's context, such as Skinner insists upon, cannot, they say, enable the historian to understand anything of the text which he could not get from studying the text itself.

Mark Bevir has spent much of the last twenty years also trying 'to counter the claim that historians must study the linguistic context of a text if they are to recover the meaning of that text' (Bevir, 1992: 278), and his most focused attack on what he used to call 'soft linguistic contextualists' - whom he has now re-branded 'conventionalists', and recently decided are a breed of 'modernists' (2009) - is to be found in 'The Errors of Linguistic Contextualism' of $1992 .^{2}$ For Bevir, Skinner's insistence that historians must study context (rather than that they may) is logically invalid. Although 'study the linguistic context of an utterance' is a 'useful heuristic maxim', doing so 'is not necessary or 
sufficient for understanding' (2000: 395; 1992: 276). Understanding, he adds, 'does not presuppose prior knowledge of the relevant linguistic context', and in fact 'there is no definite procedure that historians must follow in order to recover intentions' (1992: 297). Skinner is therefore wrong, Bevir thinks, to present his 'methods as logics of discovery' pre-requisites of understanding or knowledge - because 'no method can be a prerequisite of good history whether it be contextualism, conventionalism, or something else' (2000: 399).

Skinner is saying (Bevir thinks) - in fact, 'soft linguistic contextualists' 'insist' (1992: 290) - that historians can understand a text only if they can approach it with a correct 'prior theory' of those background conventions supposedly used by the author (1992: 288-9). Bevir then objects that sometimes people express themselves unconventionally, and we can understand them even though we can have no 'prior knowledge' of their conventions. In his example of Mrs Malaprop's 'nice derangement of epitaphs', the speaker makes herself ridiculous precisely because she gets conventional language use wrong - yet we understand her meaning perfectly well. 'We regularly surmise the meaning of unfamiliar phrases', Bevir points out, so 'it cannot be necessary for understanding that intentions should be expressed conventionally, let alone that speaker and listener should have common prior theories' (1992: 290).

The truth is, Bevir concludes, that we understand utterances thanks not to 'prior theories', but to 'passing theories' - a 'crucial distinction'. ${ }^{3}$ Because 'soft linguistic contextualists' insist on 'prior theories', their accounts of interpretation are 'mechanical'. But if we accept the importance of only 'passing theories', we accept also that 'understanding is a creative process in which we can compensate for any disparity between the meaning of a text and the prior theory we bring to that text by a leap of understanding that results in a correct passing theory' (1992: 290). Historians then... 
might be able to comprehend texts even if they do not approach them with knowledge of the precise conventions in terms of which the authors communicated their intentions; and, if historians can come to understand a text even when they have a faulty view of the conventions that apply to that text, then clearly they need not necessarily study the linguistic context of texts (1992: 290).

Furthermore, Bevir adds, it cannot even be necessary to know the context of the arguments that 'contextualists' also insist upon, because authors are not 'always out to contribute to contemporary arguments' (his example is Annie Besant's Four Great Religions). So whether they are writing without reference to other texts, or whether they are openly and explicitly responding to other texts, in neither case is it necessary 'to locate the text within a linguistic context in order to secure uptake of the author's intention in writing that text' (1992: 291). We can sometimes understand an author's intention in writing a text, Bevir concludes, even though we know nothing of the contemporary context.

Thus Bevir's critique. There is, though, a fundamental sense in which knowledge of the context is not only a 'prerequisite' for understanding, or a mere 'heuristic maxim' as Bevir thinks it is: it is actually inherent to knowing what an author thought he was saying in a text and what he thought he was doing by writing it and distributing it in the first place. Without knowing something of the 'context' in the sense I intend by this, no utterance can be understood: Annie Besant's Four Great Religions would be a complete mystery to historians of ideas, and Mrs Malaprop's lexical blunders would be not only meaningless, but also (which is worse) they would not even be funny.

What I have delineated below is an argument in support of Skinner's basic point derived from two arguments made by R. G. Collingwood, both in relation to what he 
calls his 'logic of question and answer'. Two of Collingwood's 'question and answer' arguments come into play here: the first, which we will come to in part III, is a questionand-answer theory of historical understanding. The second, which we will come to in part $\mathrm{V}$, is a question-and-answer theory of historical method. In view of both facets of Collingwood's 'logic of question and answer' Bevir's criticisms are undercut, while Skinner's claims, it seems to me, remain standing.

\section{Skinner and Collingwood}

But before we go into Collingwood's logic of question and answer, it is well to say something about Skinner's invocation of Collingwood hitherto. Skinner has conspicuously not mobilized for his own gain the arguments of Collingwood's that I am about to revive, even in his 2001 article about 'a Collingwoodian approach to the history of political thought'. This is partly, of course, because Skinner prefers to do his own thinking for himself (precisely as Collingwood instructs); but I think it is also because he does not recognize that he shares with Collingwood more than a handful of basic positions. In fact, Skinner sometimes signals certain disjunctions from Collingwood that are not really there. For example, although he says historians must, concerning the authors they are studying, 'use the ordinary techniques of historical enquiry to grasp their concepts, to follow their distinctions, to appreciate their beliefs and, so far as possible, to see things their way', (2002: 120) he also rejects Collingwood's 'doctrine of re-enactment'. In Skinner's view 'Stepping empathetically into other people's shoes and attempting (in R. G. Collingwood's unfortunate phrase) to think thoughts after them' is a 'discredited hermeneutic ambition' - and he even repeats the old commonplace that this 'empathetic process' of 'old-fashioned hermeneutics' is 'mysterious' (2002: 3). 
Regarding historical context specifically, Collingwood seems at first blanch to offer Skinner very little, and I am sure Skinner has not failed to notice this. Collingwood's Autobiography says nothing about 'context', and although he does discuss it in his Idea of History, he actually appears openly hostile to it. Here are two passages from that text which a critic sympathetic to Collingwood could even level against Skinner:

It has been said that anything torn from its context is thereby mutilated and falsified; and that, in consequence, to know any one thing, we must know its context, which implies knowing the whole universe. I do not propose to discuss this doctrine in its whole bearing, but only to remind the reader of its connexion with the view that reality is immediate experience, and its corollary that thought, which inevitably tears things out of their context, can never be true. On such a doctrine Euclid's act of thinking on a given occasion that these angles are equal would be what it was only in relation to the total context of his then experience, including such things as his being in a good temper and having a slave standing behind his right shoulder (1993: 298).

Five pages later Collingwood makes a different but related point:

[E]ven thought, in its immediacy as the unique act of thought with its unique context in the life of an individual thinker, is not the object of historical knowledge. It cannot be re-enacted; if it could, time itself would be cancelled and the historian would be the person about whom he thinks, living over again in all respects the same. The historian cannot apprehend the individual act of thought in its individuality, just as it actually happened (1993: 303). 
On the matter of context, then, there would appear to be a significant divergence between these two authors. It is obvious how one might use these apparently anticontextual sentiments to undermine Skinner's claim to Collingwood's legacy, or even to attack his claims about the importance of understanding through context outright. But it is not obvious how Collingwood might actually support 'contextualism'.

Firstly it would be a mistake to think that Collingwood is attacking in these passages 'context' in something like the form appealed to by Skinner. The kind of context Collingwood rejects the need for is the 're-experiencing' of the author's context, that is, the experiential context: the feelings the author had at the time of writing, the light by which he wrote, the pen in hand, or - as here - the slave standing behind his shoulder. None of this is relevant to historical understanding, for Collingwood, because although this kind of context is part of the author's situation 'as he sees it,' it is not the situation pertaining to the problem or question he is trying to solve or answer. Two people do not need to share an experiential context in order to think the same thoughts the same noemata. ${ }^{4}$

But secondly, and more importantly, context is, for Collingwood, not only relevant to understanding, but integral to it when what is meant by 'context' is (a) the terms of the problem the author saw himself as facing, and/or (b) the medium of expressing the solution.

III. Context I: questions and problems

No work of philosophy, Collingwood says, can be understood until the reader knows the question to which the text is intended as an answer (1939: 31; 55). 'Knowing' the actor's context in this sense - that is, as the relevant features pertaining to the problem - is part of what it means to see the agent's situation as he himself saw it (1939: 58). 
Here is how Collingwood explains, in his Autobiography, how he discovered this principle, and how he put it to use teaching the history of philosophy at Oxford. (I have provided it at length because all previous attempts to paraphrase it more succinctly have failed):

I began by observing that you cannot find out what a man means by simply studying his spoken or written statements, even though he has spoken or written with perfect command of language and perfectly truthful intention. In order to find out his meaning you must also know what the question was (a question in his own mind, and presumed by him to be in yours) to which the thing he has said or written was meant as an answer...

Now, the question ${ }^{\circ}$ To what question did So-and-so intend this proposition for an answer?' is an historical question, and therefore cannot be settled except by historical methods. When So-and-so wrote in a distant past, it is generally a very difficult one, because writers (at any rate good writers) always write for their contemporaries, and in particular for those who are likely to be interested', which means those who are already asking the question to which an answer is being offered; and consequently a writer very seldom explains what the question is that he is trying to answer. Later on, when he has become a 'classic' and his contemporaries are all long dead, the question has been forgotten; especially if the answer he gave was generally acknowledged to be the right answer; for in that case people stopped asking the question, and began asking the question that next arose. So the question asked by the original writer can only be reconstructed historically, often not without the exercise of considerable skill (1939: 31-9).

For works of philosophy the concept of a 'question' is more or less selfexplanatory. For the actions of architects or of naval strategists, though (Collingwood's 
examples - 1939: 29; 58) - or of the kinds of rhetorical performers about whom Skinner writes - we should take Collingwood's 'questions' more comprehensively, as 'problems', the 'situation' in which intervention is thought by the agent to be desirable.

'Questions' and 'problems' are by no means simple. 'A highly detailed and particularized proposition must be the answer,' Collingwood adds, 'not to a vague and generalized question, but to a question as detailed and particularized as itself (1939: 32). Collingwood calls this his 'principle of correlativity'. In order to understand Nelson's orders at the Battle of Trafalgar, for instance, the naval historian has to grasp the terms of Nelson's problem much more sophisticatedly than would be implied by saying that his problem was 'Villeneuve' - or, more essentially still, 'Napoleon'. Indeed, in order to 'understand' any single manoeuvre executed during that battle we have to see the correlative 'problem' to which it was a solution, and in as much logical, logistical detail as the captain responsible for solving it would have seen it. The same goes for Hobbes, whose context in this sense is far more than 'the Civil War'. Hobbes' 'question' would in fact require for its explication a work at least as detailed and particularized as the Leviathan itself (and, I suspect, that several times over). Hobbes's complex problem 'arises', in Collingwood's term (1939: 37), out of the 'situation' of his social and political milieu, his private readings and conversations, perhaps also private feuds over some point or other that he wanted to settle along the way, and so on. Each might add 'terms' to the problem that Leviathan is meant to solve, and each is potentially historically investigable. Skinner's own Reason and Rhetoric in the Philosophy of Hobbes is meant to show, for example, that part of the 'problem' to which Leviathan is a solution is the problem of reason alone being deficient for demonstrating truth to readers (Skinner 1996: 2-4). The rhetorical eloquence of Leviathan is, Skinner shows, partly a solution to this problem. This therefore indicates a more basic problem in Hobbes's mind, which there is no real need for him to explicate: namely, 'at present, not enough people recognise certain important 
political truths' - truths, that is, of scientia civilis. Perhaps the more 'historically remote' a problem becomes, the more work historians have to do to explain to their readers all the important ways in which the terms of that question differ from what they might have assumed. (Many of my students initially assume Hobbes's question to be 'what is the ideal state?') This is one reason why historians of ideas never, in fact, seek to 'understand' a text in its entirety. The notion that they do this is something of a dummy premise in 'methodological' arguments. They try rather to answer much more specific questions about a specific aspect of a text or an author's work more widely.

The point is that studying the 'context' in this sense is more than a mere 'heuristic maxim', because it is a necessary condition of understanding a solution that one know something, and perhaps that one know rather a lot, about the problem to which it is intended as a solution. It is a necessary condition because when it is eschewed - that is, when one does not know the question - one does not understand its solution.

Bevir thinks that if an author is writing with another particular author in mind against him, in support of him, or whatever - then he will usually say so explicitly, and there is therefore no need for Skinner's separate study or prior theories (1992: 291). Paying renewed attention to Collingwood can remind Bevir that there are always terms of an author's 'questions' that authors simply assume their readers will share. Indeed it might not even have occurred to them that it is possible to live in this world without assuming the very things they therefore quite reasonably leave unsaid. The historian, then, cannot rely on his authors to be explicit about even the most fundamental terms of their questions. Collingwood's principle of the agent's 'problem' also provides us with a good way of distinguishing between what of the writer's 'context' is not relevant to understanding his utterance, and what is integral to it: namely, if it comprises a term of the author's question, then it is integral to understanding his proposed answer. 
But even if this is right, is it how Skinner uses 'context'? Although Bevir clearly does not, does Skinner mean by 'context' something like 'problem'? It seems to me that there is a question-and-answer logic to Skinner's view of history, to 'seeing things their way', and always has been. My search among Skinner's published writings has so far produced no evidence that he contradicts this question-and-answer account of 'context'. The arguments Bevir mostly takes issue with are from Skinner's 1972 article for New Literary History, 'Motives, Intentions and the Interpretation of Texts'. It is also these arguments that, out of almost all of Skinner's, need the most extensive disentanglement in order to show how they too cohere with the logic of question and answer. The entanglement is in the word 'intention' which Skinner uses throughout. What Skinner does not say is that an intention itself has what we could call a problem and solution 'structure': formally the 'intention' is always to 'solve'. Again it is self-explanatory what this means regarding a 'question' - it is to 'state the answer'. But naval commanders, architects and rhetoricians 'solve' in a more general sense. Their 'problems', their 'difficulties', are things like large French fleets likely to invade their homeland if allowed to resupply at Naples; or a queen and public that expects a grand but sombre memorial to a world-class statesman, and a competition to be the man who designed it; or, for parliamentarians and rhetoricians, an audience or populace that needs to have its mind changed about something.

When Skinner suggests that historians as a rule should focus 'on the prevailing conventions governing the treatment of the issues or themes with which that text is concerned' (1972: 406), he is recommending simultaneously something about the study of questions and something about the study of answers. Concerning questions, the historian should be eliminating through such a study questions (or particular terms of a question) that the given author probably did not see himself facing. He might also find through such a study that his author most likely thought he was answering something 
else that was commonly dealt with according to the conventions of his environment, and which makes sense of a passage which otherwise seems to contribute nothing to the answer as it was previously understood. The motives and intentions Skinner distinguishes in 'Motives, Intentions and the Interpretation of Texts' are both terms of the author's 'problem', though the particular kind of term is precisely what the distinction clarifies.

And concerning solutions, the study of conventions might yield evidence that the author deals with a question the way he does because most authors in this period thought that this (whatever it is) was the right way to go about solving this kind of question.

My search for consistencies between Skinner and Collingwood on a questionand-answer form of 'context' has on the contrary yielded more than I can reproduce here, and it goes right back to Skinner's seminal 1969 article for History and Theory, 'Meaning and Understanding in the History of Ideas'. The common errors among historians of ideas which he describes there are, after all, simply sub-species of attributing the wrong questions to authors' proposed solutions: supposedly perennial questions, the historian's own questions, questions which only later rose to significance ('prolepsis'), etc. Moreover, the prefaces to his series The Foundations of Modern Political Thought contain explicit statements that we must see authors' problems as they saw them. 'In order to see them [texts] as answers to specific questions', he says, 'we need to know something about the society in which they were written' (Skinner, 1978: xiii). After all, 'political life itself sets the main problems for the political theorist' (Skinner, 1978: xi).

So Skinner is consistent with Collingwood's 'context' principle of 'knowing the question' - or at least there is no evidence in his writing that he is inconsistent with it. Collingwood's insistence on the necessary condition of knowing the 'question' context of an utterance, text, or action, which shows why Bevir is wrong, therefore also vindicates Skinner. 
But it seems to me moreover that Skinner does not really intend anything fundamentally extra by 'context' than what necessarily pertains to 'question and answer'. There is one obvious objection likely to be made to this: There is a prevalence of philosophy of language in Skinner of a kind that seems to be absent or different in Collingwood. Surely this, one might think, goes beyond Collingwood's account of historical understanding?

\section{Context II: language as a medium}

Skinner is concerned with the linguistic context of an action, which Collingwood is not, and it is this more than anything that makes it look as though new, 'linguistic' hermeneutics is supposed to have superseded old or 'classical' hermeneutics. ${ }^{6}$ For Skinner, I think, the post-Collingwood advances in philosophy of language, chiefly of J. L. Austin, Ludwig Wittgenstein and H. P. Grice, have rendered much of the 'oldfashioned' hermeneutics obsolete - elements such as 're-enactment'. It is from these authors rather than from Collingwood that Skinner says he takes many of his arguments and concepts.

But this 'difference' introduced by philosophy of language does not impact upon the Collingwoodian foundation of Skinner's argument about context: Skinner has simply coloured in some of the spaces left by Collingwood by providing an analysis of language as the medium through which the author expresses his intentions in order to solve the problem(s) he faces. The kind of analysis of the political language and discourse of a time Skinner advocates is supposed to provide better, more accurate, and more sophisticated historical knowledge of what agents thought they were doing because, firstly, some of the terms of an author's 'problem' will always be to do with words and terminology. 
Something of the linguistic context in which an author operates is always integral to the problem he thinks he is trying to solve. But it is also - and this is the emphasis Skinner puts on studying linguistic contexts - because terminological and rhetorical conventions are relevant aspects of the medium through which the agent 'solves'. That is to say, if part of the view the actor has of his situation is certain beliefs about what his medium of expression (his 'language') allows or constraints him to do in order to successfully solve his problem - and if those beliefs would help the historian to answer his question about what the actor thought he was doing, or why he chose to express himself in this way or in that - then those beliefs must be known to the historian.

Skinner thinks this methodological focus on the conventions and social context would be a more 'holistic' approach for the historian to take than for him to focus only on 'the individual action' (2002: 142) - which might be another attempt to signal a disjunction from Collingwood. But it seems that all he is really saying is that the language the agent has at his disposal must also be reconstructed and seen 'from the inside" in order to form conclusions about 'intentions'. Thus, on both the 'question' and the 'answer' sides of understanding texts, the kind of context Skinner is talking about is the kind of context that is integral to understanding even in Collingwoodian terms.

This does not mean, as Bevir thinks it does, that historians should always carry out a prior study of context in order to develop a 'prior theory' to take with them to the reading of a given text. (I will explain what is wrong with this 'prior theory' reading below.) It means rather something else: the 'intention' questions that historians of ideas have about the texts they are studying cannot be answered without consulting something called 'context'. As we have seen this means simply something integral to the problem as the given author saw it, or something integral to the means of solution he thought he had at his disposal. Nothing else needs to be studied. But then, by 'context' Skinner does not mean anything more. 


\section{Context and evidence}

Let us grant that the 'context' of a text, in the basic question-and-answer sense I have just outlined, might be fully comprehensible from studying only the text itself; and let us grant that there really are such texts: they were intended by the author to be fully understandable on their own terms, and more or less are. Do historians, then, ever need to study anything but the text itself, or should they, as Savile and Olsen insisted in their ripostes to Skinner in the 1970s, treat all texts as the works of authors who ought to have written everything into them that would be required for their correct interpretation?

This question can be very easily solved - or actually, I think, dissolved - by remembering a second facet of Collingwood's 'logic of question and answer', discussed in its fundamental aspect in chapter five of his Autobiography. Good historical method, like all other good scientific method, begins always with a question, Collinwood writes; and in order to answer their questions historians must use evidence, which is subtly different from what were traditionally called 'sources'. 'Anything is evidence which can be used as evidence,' Collingwood writes in The Principles of History, 'and no one can tell what is going to serve him as evidence for answering a certain question until he has formulated the question' (2001: 38).

What 'Skinnerite' historians want to know is what their authors thought they were doing when they wrote their texts. That is the question they bring to their studies, and there are few who would be willing to say that it is an illegitimate question for an historian of ideas to attempt to answer. In order to construct conclusions to a question like this, the historian has to use evidence. This is what Collingwood means as well, when he writes in his Autobiography that 'the question 'To what question did So-and-so intend 
this proposition for an answer?' is an historical question, and therefore cannot be settled except by historical methods' (1939: 39).

The text itself is obviously part of that evidence, and usually the first port of call. But to prejudge it as the only evidence relevant to constructing an answer, without finding out what other evidence there might be among what Skinner calls a 'range of extratextual aids' (Skinner 1975: 228) that could help to refine the historian's conclusion, could only be considered bad history. Yet this is what it actually means to disregard 'context' in this slightly different sense of 'what is going on around the text' or 'outside' the text: it is to prejudge evidence yet unseen. Skinner concedes that there are some texts that are 'autonomous,' and might contain everything that the historian needs to understand the author's intentions. But this is only to say that evidence useful to answering that question outside of what is offered wholly within the text is yet to be found. He points out, obviously rightly, that nothing is to be gained from assuming this that is not already covered by a contextual approach, which makes sure that such an assumption is correct. This is because the study of 'context' that Skinner is appealing to, as the historian encounters it, is not the study of a fundamentally different kind of evidence - it is just looking for more evidence potentially able to help the historian answer his question. The mistake Skinner's targets are making is sticking with the obsolete historian's distinction between 'primary' sources and 'secondary' sources. As Collingwood rightly points out in The Principles of History, the court of truth in history is other historians, who compare one's constructions with all available evidence, ${ }^{8}$ and no longer make such a distinction. It is, then, quite clear what is lost by those historians who disregard extra-textual evidence, or consider it 'secondary', but not at all clear what they gain, other than the increased risk that other historians can easily find evidence to falsify their conclusions. 
This second facet of Collingwood's logic of question and answer, in conjunction with the first, shows what has gone wrong with Bevir's criticisms of Skinner's claims about context. In short, it seems that Bevir has got the real process of actual historians' work back-to-front, because he has mistaken the question-and-answer, investigative process of historians for a process in which, when it is done properly, concepts are to be related 'logically' in a sense more abstracted from how historians go about answering their questions. He therefore views the process of interpretation from a 'logical' point of view, rather than from a 'practical' one of question and answer, and seeks to point to logical leaks in the conceptual dyke.

This is not to say that what historians do is illogical, or that logic is an illegitimate weapon against Skinner's arguments. All I mean is that when Skinner's description of a procedure in good historical work is converted into a logical series and translated back into a set of practical instructions, it does indeed begin to look very strange.

When Skinner says that it is a necessary condition of answering a question of intention that one first 'study' the conventions of a time, he is not saying that historians, to do their work properly, begin with a complete and quite separate study of those conventions in order to produce a body of knowledge which can then be taken to the 'reading' table, as one might prepare a body of notes before an important negotiation. This though is Bevir's version of Skinner's methodological prescription. When Skinner advises a study of the prevailing conventions, he is calling, in Bevir's view, for the formulation of a 'prior theory that covers the conventions in terms of which the author expressed his illocutionary intentions in writing that text' (1992: 289). This 'prior theory' is, then, something like an historian's substitute for the 'socio-cultural background' he cannot otherwise share with the subjects of his study. This principle of Bevir's - that 
'Any putative logic of discovery must rest, explicitly or implicitly, on the assumption that to understand an utterance we need to hold a correct prior theory' (2000: 399) - leads him into a further diversionary distinction between 'prior theories' and 'passing theories.' This insistence on 'prior theories' Bevir sees as the hallmark of any 'specific method', which is why none are actually necessary. (He repeats the image of 'prior knowledge' in 2000: 399).

Of course, Bevir defeats this instruction to bring a 'prior theory' (rather than a 'passing theory') to the reading of a text. But it is not Skinner's anyway, because the 'study of context' is not supposed to produce, as Bevir reads, a 'body of knowledge' (1992: 289), a substitute socio-cultural background for the historian's reading. It is rather - and this is all Skinner means - that the historian's investigation of context leads from his question about what an utterance means to some idea about what the author's question or problem was. This is because his first question about an utterance, necessary to 'understanding' in the sense in which he pursues it, is 'What is this an answer to?' or, 'What was this supposed to solve?' A study aimed at elucidating the question in sufficient detail is a study of context, but it cannot take place before the historian has even formulated his question. Skinner's only mistake is inaccurately calling the study of context a 'separate form of study'. It is not separate at all: it serves the historian's original question. Indeed he acknowledges this too in volume one of his Foundations: "When we attempt in this way to locate a text within its appropriate context, we are not merely providing historical 'background' for our interpretation; we are already engaged in the act of interpretation itself (1978: xiv).

Bevir might, if he wishes, call the answer to the 'question' question itself a 'prior theory', as indeed it is: it is the historian's theory about what the author's question was. But calling it such will only serve to yield an important exception to his rule about 'prior theories' never being necessary. Indeed, it shows that such a theory is necessary in the 
even stronger sense that it is unavoidable. In reading a text one always assumes, whether consciously or not, the question to which it is an answer. This 'studying' and 'theorizing' is inevitable as part of what 'reading' is, but it can be done well or badly. It is done well when it is done deliberately and investigatively, studying as much evidence as is necessary to find the best answer. It is done badly when done unreflectively, perhaps even unconsciously, with the text itself constituting the full body of 'evidence' studied by the reader, the historian, and even then not terribly thoroughly. My point is not that in order to understand anything one must perform this kind of study as thoroughly as possible every time. It is rather my intention to explain why, where attempts to 'understand' are concerned, Bevir is wrong to think that this 'study' and its 'theory' can ever be bypassed at all.

When Bevir does turn his discussion to the 'historical' process of questionevidence-answer, he is forced to concede that the context can be useful for understanding a text. Indeed, he is prepared to give a lot of ground here:

The linguistic context might even provide a crucial piece of evidence that will lead a historian to see the meaning of a particular text. Further, there is a sense in which the fact that the linguistic context might provide a crucial piece of evidence means that prudent historians always will examine the linguistic context of texts that interest them (1992: 293-4).

But Bevir is only prepared to give this ground because he thinks he has kept the process of historical work, where historians are prudent and evidence is 'useful', separate from the logical process in which 'necessary conditions' are to be discussed. This is because (aptly enough) the question to which his 'methodological' writing is an answer is quite different to that tackled by Skinner. It is clear from his 1999 work, The Logic of the 
History of Ideas, exactly how Bevir's 'problem' differs from that of Skinner - and perhaps always has differed. One of the assumptions built into the 'problem' common to all of Skinner's writings is that we are discussing the procedures by which historians of ideas answer their questions - that is, do their work. Bevir does not really share this, because one of the assumptions that defines the problem common to all of his work is that 'the history of ideas' as a discipline is to be corrected by analysing and defining the concepts used in methodological debates, with the results providing 'normative' definitions for scholars (Bevir, 1999: 9, 10, 16). In the case of the concept of 'context' however, this framing of the question has not served Bevir well, because he finds himself describing and attacking something that would form neither a necessary nor even a useful part of any historian's procedure: namely, the task of studying an amorphous network of meanings, ideas, assumptions, conventions, and words, with no specific idea of what kind of evidence it is that is being sought amongst it all. It would lead to something Skinner, in his work on Hobbes, explicitly warns historians against: drowning an author 'in an ocean of discourse' (1996: 8).

\section{Conclusions}

Our conclusions from all this fall into two sets: those conclusions concerning the present, and those concerning the past. Those concerning the present are that, firstly, studying the historical context is a necessary condition of understanding, when (a) what the historian wants to 'understand' is what the author thought he was doing in and with a text, and when (b) 'context' includes either or both of the terms of the problem he thought he faced, and/or the medium he thought he had at his disposal for solving it. Secondly, the study of what is 'outside' the text is no more or less legitimate or useful per se than the 
study of the text itself, because, for the historian with a question to answer, there is no meaningful distinction to be made between different types of evidence.

A third conclusion we can add is that, if his treatment of 'context' is representative, Bevir's failure to think in the question-and-answer terms of Collingwood's historian with questions to answer is a severe compromise to the efficacy and purport of his writings concerning the history of ideas. On 'context' he has been consistently misled by the term 'prior theory' and by the notion of the 'separate study' which is thought to produce it. This mistake can only be made if we lose sight of the actual investigative character of what historians of ideas do - or, at least, should do - and attempt to substitute for methodology analyses of conceptual logic and resultant normative conceptual definitions. In contrast, it is a virtue of Skinner's writings on historical method that they, like Collingwood's, are never considered and composed except from this point of view. It is to be admitted, though, that Skinner's own language has invited rather too literal an interpretation of his 'priority' metaphor: that 'before' you might read, you must study 'context'.

The second set of conclusions, those regarding 'the past', are as follows. I have not argued that all of Skinner's arguments about method or about the importance to studying 'context' are secretly based on Collingwood's 'logic of question and answer'. But we can conclude that Skinner is in agreement with Collingwood on points directly concerning his claims about the necessity for understanding a past text of understanding historical context. We can also conclude that this agreement has generally not been recognized - perhaps even by Skinner himself - and that this is probably partly because of Collingwood's own dismissal of a version of 'knowing-in-context' (a false version) according to which 'context' means the lives, experiences, and mental worlds of individual thinkers. But when false definitions of 'context' are stripped away, and when we refocus on what historians of ideas ask about texts and how they go about answering 
those questions, it becomes clear that - as Collingwood always wrote, and as Skinner has always maintained - the historical context of texts has, just like the work of prudent historians themselves, a question-and-answer logic.

\section{ACKNOWLEDGEMENTS}

I am grateful to Iain Hampsher-Monk and Edward Skidelsky for their general supervision of all my projects, including this one, no matter how hare-brained they have sometimes been. I owe more specific thanks to Robert Lamb for his detailed comments on my work in this field; for his encouragement and advice on publishing some of it; and for the red-blooded exchanges we have had (and will I hope continue to have) over certain tracts of this battlefield.

\section{FUNDING}

This article is based on doctoral research funded by the Arts and Humanities Research Council [grant number AH/H020314/1]

\section{NOTES}

${ }^{1}$ Savile, Anthony (1972) 'The Place of Intention in the Concept of Art', in Harold Osborne (ed.) Aesthetics. Oxford: Oxford University Press, 158-76. (Skinner points particularly to pp. 170-1.) See Skinner, 1974: 217. Olsen, Stein Hangom (1973) 'Authorial Intention', British Journal of Aesthetics 13: 219-31. Skinner points particularly to p. 229.

${ }^{2}$ His argument in 'The Role of Contexts in Understanding and Explanation' eight years later is broadly the same, and the chapter on 'Meaning' in his Logic of the History of Ideas is 
obviously another revised version of the same thing. A later piece meanwhile, 'Contextualism: From Modernist Method to Post-analytic Historicism?', replaces argument with a loaded quasi-historical story of how such 'modernist ambitions' have been 'eroded' and how 'modernist method' has 'lost plausibility' (2009: 221-222). The question there is 'what shall we do now?'

${ }^{3}$ The distinction is repeated (and so is the Mrs Malaprop example) in Bevir, 2000: 399.

${ }^{4}$ For this usage see Collingwood, 2001: 223. See also van der Dussen's introduction to Collingwood, 1993: xxxvii.

${ }^{5}$ The notion goes right back to Collingwood's first published book, Religion and Philosophy, of 1916. See Collingwood, 1997: 42-3.

${ }^{6}$ See for instance Lamb, 2009: 8.

${ }^{7}$....as must all of the things Charles Taylor asks Skinner about in his insouciant chapter in Meaning and Context. Taylor writes: 'The challenge here as it relates to Skinner's methodology could be put in this way: telling us to identify what the author of a text is doing, how he is intervening in the conflicts of his day, is not enough. We can't take it for granted that we already know how to do this for an age sufficiently different from our own. Perhaps we need to learn more about the kinds of conflicts that were, what was at stake in them, the kinds of moves you could make, and what represented victory or defeat.' See Taylor, 1988: 226-7.

${ }^{8}$ In The Idea of History Collingwood writes: 'the historian's picture stands in a peculiar relation to something called evidence. The only way in which the historian or any one else can judge, even tentatively, of its truth is by considering this relation; and, in practice, what we mean by asking whether an historical statement is true is whether it can be justified by an appeal to the evidence: for a truth unable to be so justified is to the historian a thing of no interest' (1993: 246).

\section{BIBLIOGRAPHY}

Bevir, M. (1992) 'The Errors of Linguistic Contextualism', History and Theory 31: 276-298

Bevir, M. (1999) The Logic of the History of Ideas. Cambridge: Cambridge University Press.

Bevir, M. (2000) 'The Role of Contexts in Understanding and Explanation', Human Studies 23: 395-411

Collingwood, R. G. (1933) An Essay on Philosophical Method. Oxford: Oxford University Press.

Collingwood, R. G. (1939) An Autobiography. Oxford: Oxford University Press.

Collingwood, R. G. (1993) W. J. van der Dussen, (ed.) The Idea of History: with lectures 1926-1928. Oxford: Oxford University Press.

Collingwood, R. G. (1997) Religion and Philosophy. Bristol: Thoemmes Press.

Collingwood, R. G. (2001) W. H. Dray \& W. J. van der Dussen (eds) The Principles of History and other writings in philosophy of history. Oxford: Oxford University Press. 
Lamb, R. (2009) 'Quentin Skinner's Revised Historical Contextualism: A Critique', History of the Human Sciences 22: 51-73

Skinner, Q. (1969) 'Meaning and Understanding in the History of Ideas', History and Theory 8: 3-53

Skinner, Q. (1974) 'Some Problems in the Analysis of Political Thought and Action,' Political Theory 2, 3: 277-303

Skinner, Q. (1975) 'Hermeneutics and the Role of History', New Literary History 7: 209-232

Skinner, Q. (1978) The Foundations of Modern Political Thought, vol. 1, The Renaissance. Cambridge: Cambridge University Press.

Skinner, Q. (1996) Reason and Rhetoric in the Pbilosopby of Hobbes. Cambridge: Cambridge University Press.

Skinner, Q. (2001) 'The rise of, challenge to and prospects for a Collingwoodian approach to the history of political thought', in D. Castiglione and I. W. HampsherMonk (eds) The History of Political Thought in National Context. Cambridge: Cambridge University Press, pp. 175-188

Skinner, Q. (2002) Visions of Politics, vol. 1, Regarding Method. Cambridge: Cambridge University Press.

Taylor, C. (1988) 'The hermeneutics of conflict', in J. Tully (ed.) Meaning and Context: Quentin Skinner and his Critics. Princeton: Princeton University Press, pp. 218-228

\section{BIOGRAPHICAL NOTE}

Christopher Fear is currently writing his Ph.D. on R. G. Collingwood's philosophy of history under the supervision of Iain Hampsher-Monk and Edward Skidelsky at the University of Exeter, where he also teaches 17th-, 18th- and 19th-century political theory. 